\title{
Rancang Bangun Alat Bantu Penyusun Cetak Biru Jaringan Induk Komunikasi dan Informasi Berbasis Peta Digital Studi Kasus Kabupaten Lombok Utara
}

\author{
(Design and Develop Map Based Tool for Creating ICT Master Plan Case \\ Study North Lombok Regency)
}

\author{
Ni Wayan Eka Widiyani, Ida Bagus Ketut Widiartha, Sri Endang Anjarwani \\ Dept Informatics Engineering, Mataram University \\ Jl. Majapahit 62, Mataram, Lombok NTB, INDONESIA \\ Email: ayaneka@gmail.com,widi@unram.ac.id, endang@unram.ac.id
}

\begin{abstract}
North Lombok regency is a newly created district and requires master plan to accelerate the development process especially in Information and Communication Technology (ICT). The purpose of this study is to build a system that can provide information about the Government of the location of services, routes, distances and altitudes to determine the network infrastructure at each location of government services. The system was developed by the Code Igniter Framework and used the PHP and HTML programming languages, also using the Google Maps API to display routes, distances, and altitudes. In this research using 5 steps as system development, that is defining system requirements, system planning, coding and implementation, testing and documentation. Users can specify the types of networks in each location of government services based on route results, distance and altitude using the Google Maps API. This system uses black box and MOS for testing. The results of black box testing function in the system has been running well and MOS results got $53.54 \%$ of the answers agreed for this system
\end{abstract}

Key words: Geographic Information System, Network, Google Maps API, Master Plan

\section{INTRODUCTION}

Beberapa tahun belakangan ini sistem informasi berkembang sangat pesat dan menjadi kebutuhan di lingkungan organisasi. Dengan adanya sistem informasi dapat membantu pemerintah untuk mendapatkan informasi pemerintahan. Dalam rangka mewujudkan hal tersebut dibutuhkan perencanaan pengembangan teknologi sistem informasi yang diawali dengan pembuatan master plan infrastruktur jaringan.

Saat ini pemerintahan Kabupaten Lombok Utara masih belum memiliki alat bantu master plan infrastruktur jaringan. Hal ini dikarenakan sebagian besar Kabupaten Lombok Utara memiliki jarak antar SKPD cukup jauh karena kondisi geografis yang berbukit dan pantai.

Oleh karena itu, diperlukan suatu sistem informasi pengukuran jarak, rute dan ketinggian yang menggunakan teknologi Google Map API. Pengukuran ini akan bergantung pada analisa data kondisi geografis saat ini untuk menentukan jarak, rute dan ketinggian, sehingga diharapkan dapat membantu memberikan informasi yang tepat dan membuat master plan infrastruktur jaringan di Kabupaten Lombok Utara.

\section{PENELITIAN TERKAit}

Sistem informasi Geografis (SIG) merupakan salah satu informasi yang terkait dengan data-data yang berkaitan dengan permukaan bumi. SIG banyak melibatkan data grafis atau data spatial dan data attribute (tematik) seperti sumber daya alam, lingkungan dan lainlain, untuk membantu menyajikan data dari real word kedalam komputer.

Penelitian terkait SIG sangat banyak dilakukan mulai dari proses perencanaan [1], implementasi pada bidang sistem tenaga [2], peramalan[3], pencarian rute dengan obyek wisata kuliner[4], sampai pada pendataan menara telekomunikasi [5][6], dan coverage area menara telekomunikasi tersebut[7]. Alat bantu pengembangan ada yang banyak digunakan adalah menggunakan produk Esri[1], dan ada juga lebih banyak melakukan eksplorasi kemampuan Google Map (GMAP) dengan application programming interface (API)[8]-nya. Dengan memanfaatkan tool yang disiapkan oleh GMAP bisa dilakukan visualisasi 4 dimensi (ruang dan waktu)[9], diintegrasikan dengan mesin cerdas[10], dan diintegrasikan dengan sistem informasi lainnya[11].

Pada penelitian ini, dengan memanfaatkan GMAP API, dibangun sebuah tool untuk melakukan perencanaan jaringan telekomunikasi di wilayah kabupaten Lombok Utara (NTB). Pada penelitian ini dibuat tool untuk membuat jaringan, segmentasi jaringan, ketinggian suatu titik untuk melihat line of sight (LoS) dan lain-lain. 


\section{METODOLOGI}

Proses pengembangan sistem menggunakan 5 tahap pengembangan diantaranya pendefinisian kebutuhan sistem, perancangan sistem, coding dan implementasi, pengujian, dan dokumentasi yang dapat dilihat pada Gambar 1

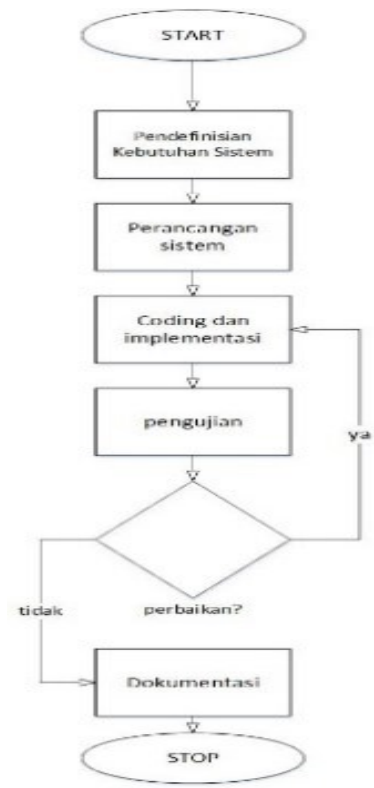

Gambar 1. Flowchart pengembangan sistem

\section{A. Rancangan Sistem}

Tahap ini adalah dilakukan perancangan sistem menggunakan use case diagram yang menggambarkan proses yang dapat dilakukan oleh pengguna. Perancangan use case perlu dilakukan agar para pengguna mengetahui fitur-fitur apa saja yang dapat dilakukan di dalam sistem. Perancangan use case dapat dilihat pada Gambar 2

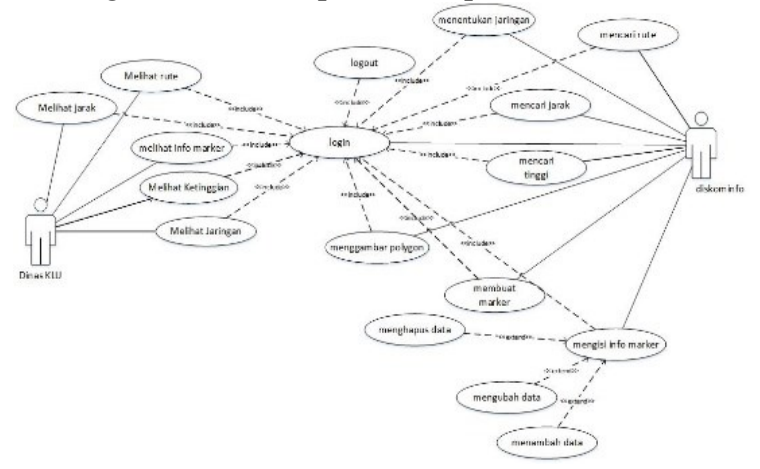

Gambar 2. Use Case Diagram

\section{B. Perancangan Database}

Tahap selanjutnya adalah perencanaan database. Datadata yang ada pada sistem ini seluruhnya akan disimpan dalam satu database, sehingga data menjadi terintegrasi. Perancangan database perlu dilakukan agar penyimpanan data dapat dilakukan secara optimal dan mengurangi adanya duplikasi data yang juga dapat meminimalkan media penyimpanan. Perancangan database sistem dapat dilihat pada Gambar 3.

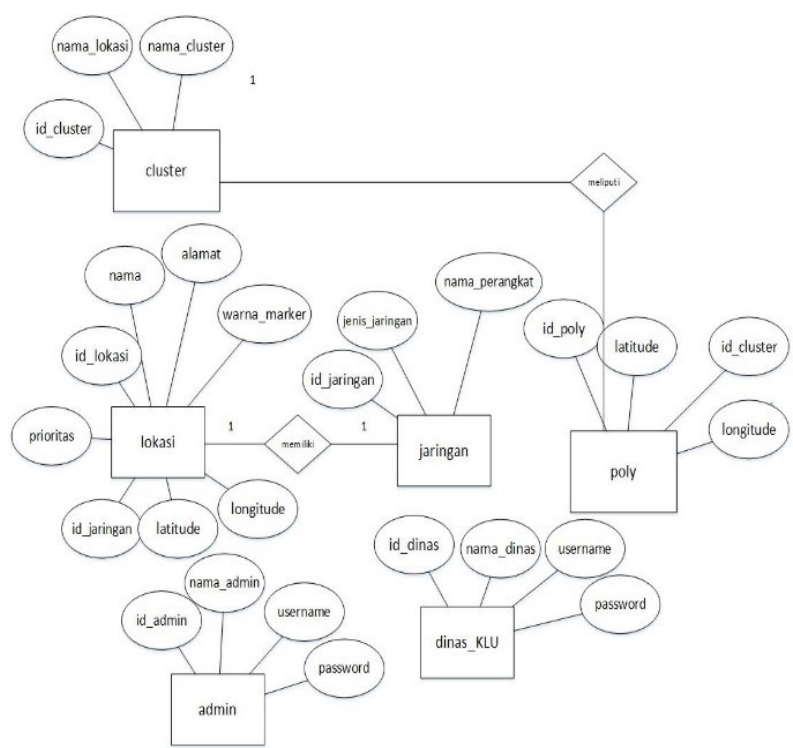

Gambar 2. Entity Relationships Diagram

\section{HASIL DAN PEMBAHASAN}

\section{A. Implementasi Interface}

Implementasi yang dijabarkan adalah hasil implementasi sistem yang telah dirancang. Hasil dari implementasi tersebut telah diubah kedalam bahasa pemrograman PHP dan HTML. Berikut hasil dari implementasi interface dapat dilihat pada Gambar 4, gambar 5, Gambar 6, dan Gambar 7

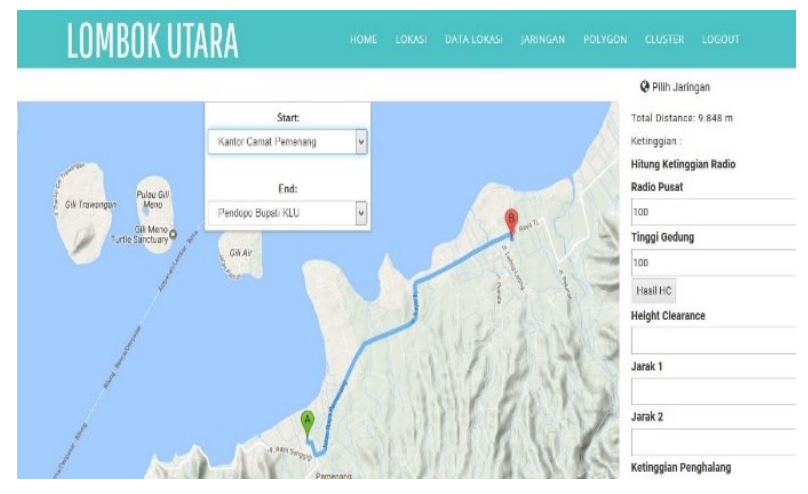

Gambar 4. Implementasi tampilan route dan jarak
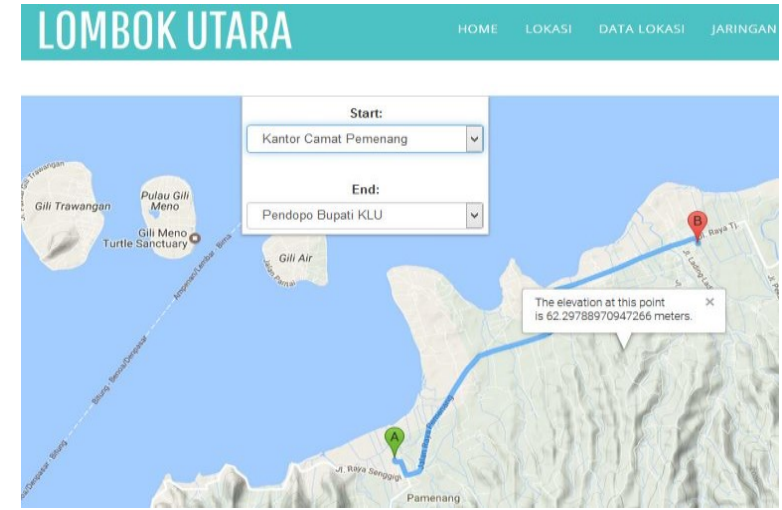

Gambar 5. Implementasi tampilan ketinggian 


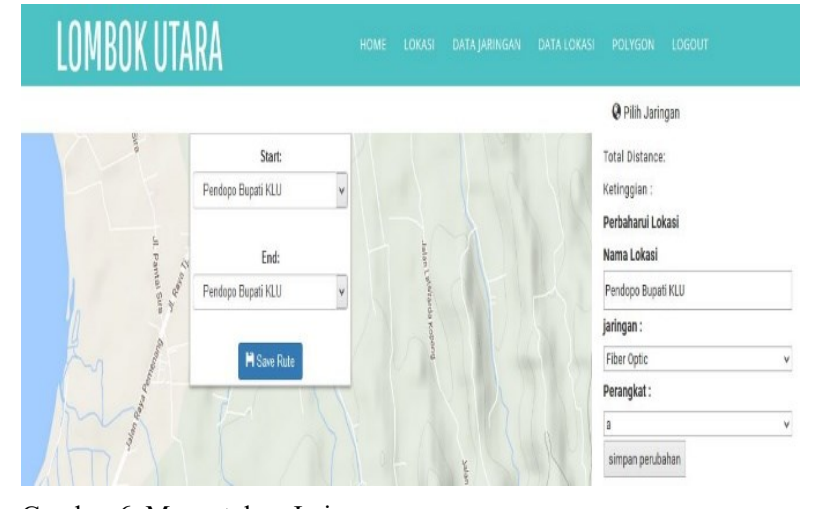

Gambar 6. Menentukan Jaringan

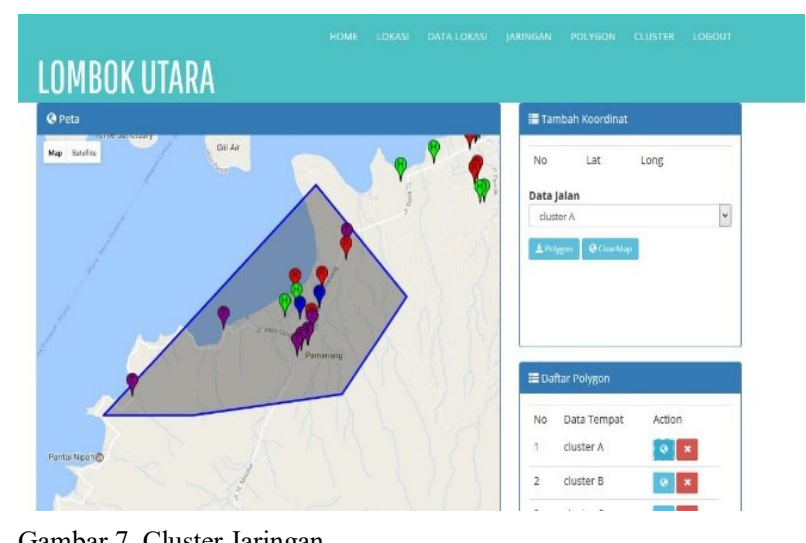

Gambar 7. Cluster Jaringan

\section{B. Pengujian Sistem}

\section{B.1 Uji fungsionalitas}

Untuk menguji fungsionalitas sistem digunakan Metode black box. Metode ini merupakan metode pengujian yang menguji fungsi-fungsi didalam sistem untuk menentukan apakah fungsi-fungsi tersebut sudah berjalan sesuai harapan atau tidak.

\section{B.2 Uji pendapat pengguna}

Pengujian ini menggunakan kuesioner, dilakukan dengan mencari responden untuk mencoba menjalankan sistem, lalu memberikan pendapatnya dalam kuesioner yang telah disiapkan. Tujuan dari kuesioner ini adalah mengetahui bagaimana kualitas sistem dilihat dari sisi pengguna

Pengujian ini dilakukan oleh 30 responden yang dipilih secara acak yang terdiri dari 26 orang masyarakat umum sebagai pengguna yang dapat melihat sistem, dan 4 orang dari Dinas Komunikasi dan Informasi Kabupaten Lombok Utara. Hasil dari jawaban responden nantinya dihitung dan ditarik kesimpulan mengenai hasil pengujian sistem. Kuesioner pengujian sistem terdiri dari delapan pernyataan, yaitu:

1. Komposisi warna website enak dilihat

2. Desain tampilan mudah dipahami

3. Sistem ini dapat memberikan informasi lokasi/koordinat SKPD

4. Sistem ini dapat memberikan informasi mengenai rute
5. Sistem ini dapat memberikan informasi mengenai jarak

6. Sistem ini dapat memberikan informasi mengenai ketinggian suatu lokasi

7. Sistem ini dapat memberikan informasi mengenai jaringan yang terpasang dan jaringan yang direncanakan pada masing-masing lokasi di Kabupaten Lombok Utara

8. Sistem ini dapat digunakan sebagai media untuk merencanakan dan memantau pembangunan backbone di Kabupaten Lombok Utara

Selanjutnya dari pernyataan tersebut, responden diminta untuk menjawab dengan nilai-nilai tertentu, diantaranya:

$1=$ Sangat tidak setuju.

2 = Tidak setuju.

$3=$ Cukup.

$4=$ Setuju

$5=$ Sangat setuju

Berdasarkan jawaban tersebut, langkah selanjutnya adalah menghitung persentase dari setiap jawaban yang diberikan oleh pengguna di setiap pernyataan. Rumus untuk menghitung persentase nilai adalah sebagai berikut:

$$
\mathrm{PR}=\mathrm{J} / \mathrm{N} * 100 \%
$$

Dimana:

$\mathrm{J} \quad$ : total nilai jawaban yang diberikan responden pada setiap nomor,

$\mathrm{N}$ : jumlah responden dan

PR : persentase jawaban responden.

Untuk menghitung persentase rata-rata dari setiap poin jawaban, perhitungan yang digunakan adalah menggunakan rumus sebagai berikut:

$$
\text { Rerata Persentase responden }=\frac{\sum_{i=0}^{n} P R_{i}}{K}
$$

dengan $K$ adalah total pertanyaan.

Jadi persentase responden terhadap jawaban kuesioner yaitu, sangat tidak setuju, tidak setuju, cukup, setuju dan sangat setuju dapat dihitung secara keseluruhan dan didefinisikan sebagai nilai rata-rata.

Dengan menggunakan rumus perhitungan diatas, perhitungan untuk hasil jawaban pengguna pada setiap pertanyaan pada kuesioner dapat dilihat pada Tabel I, Tabel II, Tabel III, Tabel IV, Tabel V, Tabel IV, Tabel VII dan Tabel VIII sebagai berikut:

TABEL I. Hasil Pengujian PernyataAn 1

\begin{tabular}{|c|c|c|c|}
\hline $\begin{array}{c}\text { Kategori } \\
\text { Jawaban }\end{array}$ & $\begin{array}{c}\text { Jumlah } \\
\text { Jawaban }\end{array}$ & $\begin{array}{c}\text { Jumlah } \\
\text { Responden }\end{array}$ & Persentase \\
\hline Sangat setuju & 6 & 30 & $20 \%$ \\
\hline Setuju & 16 & 30 & $53.33 \%$ \\
\hline Cukup & 7 & 30 & $23.33 \%$ \\
\hline Tidak setuju & 1 & 30 & $3.33 \%$ \\
\hline $\begin{array}{c}\text { Sangat tidak } \\
\text { setuju }\end{array}$ & 0 & 30 & $0 \%$ \\
\hline
\end{tabular}


TABEL II. Hasil Pengujian PernyataAn 2

\begin{tabular}{|c|c|c|c|}
\hline Kategori Jawaban & $\begin{array}{c}\text { Jumlah } \\
\text { Jawaban }\end{array}$ & $\begin{array}{c}\text { Jumlah } \\
\text { Responden }\end{array}$ & Persentase \\
\hline Sangat setuju & 15 & 30 & $50 \%$ \\
\hline Setuju & 12 & 30 & $40 \%$ \\
\hline Cukup & 2 & 30 & $6.66 \%$ \\
\hline Tidak setuju & 1 & 30 & $3.33 \%$ \\
\hline $\begin{array}{c}\text { Sangat tidak } \\
\text { setuju }\end{array}$ & 0 & 30 & $0 \%$ \\
\hline
\end{tabular}

TABEL III. Hasil Pengujian PernyataAn 3

\begin{tabular}{|c|c|c|c|}
\hline $\begin{array}{c}\text { Kategori } \\
\text { Jawaban }\end{array}$ & $\begin{array}{c}\text { Jumlah } \\
\text { Jawaban }\end{array}$ & $\begin{array}{c}\text { Jumlah } \\
\text { Responden }\end{array}$ & Persentase \\
\hline Sangat setuju & 12 & 30 & $40 \%$ \\
\hline Setuju & 17 & 30 & $56.66 \%$ \\
\hline Cukup & 1 & 30 & $3.33 \%$ \\
\hline Tidak setuju & 0 & 30 & $0 \%$ \\
\hline $\begin{array}{c}\text { Sangat tidak } \\
\text { setuju }\end{array}$ & 0 & 30 & $0 \%$ \\
\hline
\end{tabular}

TABEL IV. Hasil Pengujian PernyataAn 4

\begin{tabular}{|c|c|c|c|}
\hline $\begin{array}{c}\text { Kategori } \\
\text { Jawaban }\end{array}$ & $\begin{array}{c}\text { Jumlah } \\
\text { Jawaban }\end{array}$ & $\begin{array}{c}\text { Jumlah } \\
\text { Responden }\end{array}$ & Persentase \\
\hline Sangat setuju & 13 & 30 & $43.33 \%$ \\
\hline Setuju & 15 & 30 & $50 \%$ \\
\hline Cukup & 2 & 30 & $6.66 \%$ \\
\hline Tidak setuju & 0 & 30 & $0 \%$ \\
\hline $\begin{array}{c}\text { Sangat tidak } \\
\text { setuju }\end{array}$ & 0 & 30 & $0 \%$ \\
\hline
\end{tabular}

TABEL V. Hasil Pengujian Pernyataan 5

\begin{tabular}{|c|c|c|c|}
\hline $\begin{array}{c}\text { Kategori } \\
\text { Jawaban }\end{array}$ & $\begin{array}{c}\text { Jumlah } \\
\text { Jawaban }\end{array}$ & $\begin{array}{c}\text { Jumlah } \\
\text { Responden }\end{array}$ & Persentase \\
\hline Sangat setuju & 16 & 30 & $53.33 \%$ \\
\hline Setuju & 13 & 30 & $43.33 \%$ \\
\hline Cukup & 1 & 30 & $3.33 \%$ \\
\hline Tidak setuju & 0 & 30 & $0 \%$ \\
\hline $\begin{array}{c}\text { Sangat tidak } \\
\text { setuju }\end{array}$ & 0 & 30 & $0 \%$ \\
\hline
\end{tabular}

TABEL VI. Hasil Pengujian PernyataAn 6

\begin{tabular}{|c|c|c|c|}
\hline $\begin{array}{c}\text { Kategori } \\
\text { Jawaban }\end{array}$ & $\begin{array}{c}\text { Jumlah } \\
\text { Jawaban }\end{array}$ & $\begin{array}{c}\text { Jumlah } \\
\text { Responden }\end{array}$ & Persentase \\
\hline Sangat setuju & 10 & 30 & $33.33 \%$ \\
\hline Setuju & 18 & 30 & $60 \%$ \\
\hline Cukup & 2 & 30 & $6.66 \%$ \\
\hline Tidak setuju & 0 & 30 & $0 \%$ \\
\hline $\begin{array}{c}\text { Sangat tidak } \\
\text { setuju }\end{array}$ & 0 & 30 & $0 \%$ \\
\hline
\end{tabular}

TABEL VII. Hasil Pengujian PernyataAn 7

\begin{tabular}{|c|c|c|c|}
\hline Kategori Jawaban & $\begin{array}{c}\text { Jumlah } \\
\text { Jawaban }\end{array}$ & $\begin{array}{c}\text { Jumlah } \\
\text { Responden }\end{array}$ & Persentase \\
\hline Sangat setuju & 1 & 4 & $25 \%$ \\
\hline Setuju & 2 & 4 & $50 \%$ \\
\hline Cukup & 1 & 4 & $25 \%$ \\
\hline Tidak setuju & 0 & 4 & $0 \%$ \\
\hline $\begin{array}{c}\text { Sangat tidak } \\
\text { setuju }\end{array}$ & 0 & 4 & $0 \%$ \\
\hline
\end{tabular}

TABEL VIII. Hasil Pengujian Pernyataan 8

\begin{tabular}{|c|c|c|c|}
\hline Kategori Jawaban & $\begin{array}{c}\text { Jumlah } \\
\text { Jawaban }\end{array}$ & $\begin{array}{c}\text { Jumlah } \\
\text { Responden }\end{array}$ & Persentase \\
\hline Sangat setuju & 0 & 4 & $0 \%$ \\
\hline Setuju & 3 & 4 & $75 \%$ \\
\hline Cukup & 1 & 4 & $25 \%$ \\
\hline Tidak setuju & 0 & 4 & $0 \%$ \\
\hline $\begin{array}{c}\text { Sangat tidak } \\
\text { setuju }\end{array}$ & 0 & 4 & $0 \%$ \\
\hline
\end{tabular}

Berdasarkan hasil persentase tersebut ditampilkan pada Gambar 8.

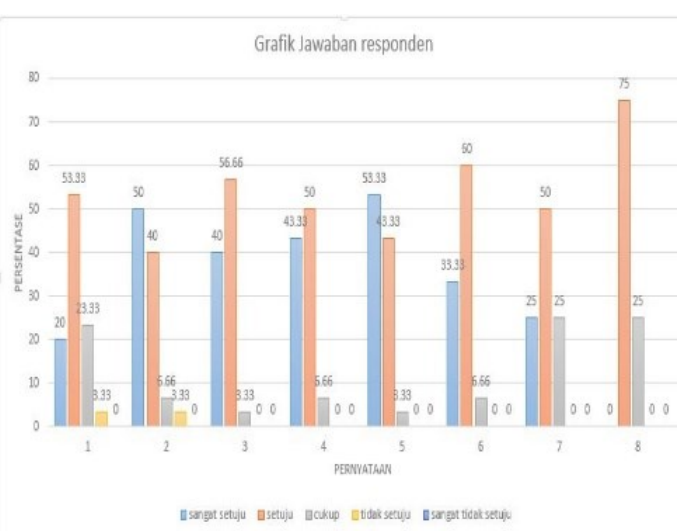

Gambar 8. Grafik Jawaban Responden

Dari keseluruhan jawaban responden dapat dihitung persentase rata-rata sebagai berikut dapat dilihat pada Tabel IX

TABEL IX. RATA- RATA JAWABAN RESPONDEN

\begin{tabular}{|c|c|}
\hline Kategori Jawaban & Persentase Rata-rata \\
\hline Sangat setuju & $33.12 \%$ \\
\hline Setuju & $53.54 \%$ \\
\hline Cukup & $12.49 \%$ \\
\hline Tidak setuju & $0.83 \%$ \\
\hline Sangat tidak setuju & $0 \%$ \\
\hline
\end{tabular}

\section{KESIMPULAN}

Berdasarkan penelitian dan pembangunan sistem yang dilakukan, dapat ditarik beberapa kesimpulan dalam pembangunan "Rancang Bangun Sistem Informasi Geografis Kabupaten Lombok Utara Sebagai Alat Bantu Untuk Menyusun Cetak Biru Jaringan Induk Komunikasi Dan Informasi Pemerintah Kabupaten Lombok Utara" diantaranya:

1. Pembuatan sistem dengan lima tahapan, yaitu pendefinisian kebutuhan, perancangan sistem, coding dan implementasi, pengujian, serta dokumentasi sistem. Sistem dibangun dengan Bahasa pemrograman HTML dan PHP serta dengan menggunakan framework CodeIgniter.

2. Sistem yang telah dibuat dapat menemukan rute antar dua lokasi, jarak antar dua lokasi serta ketinggian suatu titik yang menjadi dasar penentuan jaringan pada suatu lokasi SKPD di Kabupaten Lombok Utara. 
3. Berdasarkan hasil pengujian black box menunjukkan bahwa seluruh fungsi telah berjalan sesuai dengan sistem yang diusulkan.

4. Berdasarkan hasil pengujian MOS menunjukkan rata-rata jawaban responden menyatakan setuju sejumlah $53.54 \%$ terhadap sistem yang telah dibuat.

\section{DAFTAR PUSTAKA}

[1] ESRI, "GIS Solutions for Urban dan Regional Planning Designing and Mapping the Future of Your Community with GIS," Esri, 2006.

[2] G. Celli, N. Chowdhury, F. Pilo, G. G. Soma, M. Troncia, dan I. M. Gianinoni, "Multi-Criteria Analysis for decision making applied to active distribution network planning," Electr. Power Syst. Res., vol. 164, pp. 103-111, Nov. 2018.

[3] S. Chicherin, A. Volkova, and E. Latõšov, "GIS-based optimisation for district heating network planning," Energy Procedia, vol. 149, pp. 635-641, Sep. 2018.

[4] J. E. Prasetyo, I. B. K. Widiartha, dan M. A. Albar, "Sistem Informasi Geografis Pencarian Lokasi Wisata Kuliner Terdekat di Kota Mataram Berbasis Website," J. Comput. Sci. Informatics Eng., vol. 1, no. 1, p. 65, Jan. 2018.

[5] Muliyadi, D. B. Rendra, dan F. Darma, "Aplikasi Pendataan Menara Telekomunikasi Berbasis Gis Di Kota Serang,” J. PROSISKO, vol. 2, no. 2, pp. 69-73, 2015.

[6] T. Thamrin dan W. Susanty, "Sebaran Menara
Telekomunikasi Seluler Bersama Berbasis GIS (Geographic Information System) di Wilayah Kabupaten Lampung Tengah," Expert, vol. 7, no. 2, Dec. 2017.

[7] B. A. Virgunzena, P. K. Sudiarta, dan I. M. A. Suyadnya, "Rancang Bangun Aplikasi Pemetaan Coverage Area Berbasis Web Responsive Sebagai Alat Simulasi Perencanaan Pembangunan Tower Telekomunikasi," Maj. Ilm. Tek. Elektro, vol. 13, no. 2, p. 1, 2014.

[8] S. Hu and T. Dai, "Online Map Application Development Using Google Maps API, SQL Database, and ASP .NET," Int. J. Inf., vol. 3, no. 3, pp. 102-110, 2013.

[9] Y. Wang, G. Huynh, and C. Williamson, "Integration of Google Maps/Earth with microscale meteorology models and data visualization," Comput. Geosci., vol. 61, pp. 23 31, Dec. 2013.

[10] I. B. K. Widiartha, S. E. Anjarwani, dan F. Bimantoro, "Traveling salesman problem using multi-element genetic algorithm," in 2017 11th International Conference on Telecommunication Systems Services and Applications (TSSA), 2017, pp. 1-4.

[11] R. Parahita, I. B. K. Widiartha, dan A. Zubaidi, "Sistem Informasi Perhotelan Berbasis Web Service, Studi Kasus Di Pulau Lombok," J. Comput. Sci. Informatics Eng., vol. 1, no. 1, p. 46, Jan. 2018. 